\title{
The Conservation of Sixteenth Century Church Santa Maria of Montedecoro in Maddaloni
}

\author{
Mariano Nuzzo², Mariateresa Guadagnuolo', Giuseppe Faella ${ }^{1}$, Marianna Aurilio ${ }^{1}$ \\ ${ }^{1}$ Dipartimento di Architettura e Disegno Industriale, Università degli Studi della Campania "L. Vanvitelli", \\ Scuola Politecnica e delle Scienze di Base, Abbazia di San Lorenzo ad Septimum, 81031, Aversa, Italy
}

${ }^{2}$ Consorzio di Ricerca Laocoonte, vico Tansillo 6, Teano, Italy

Email:m.guadagnuolo@unicampania.it

\begin{abstract}
Santa Maria of Montedecoro is a sacral complex located in Maddaloni, in the south of Italy, and is one of the most important historical monuments of the city. Built in the sixteenth century, the monastic organism consists of an aggregate structure, including the church dedicated to the Virgin Mary, the bell tower which is set back from the church, the sacristy, the parsonage. This paper concerns the analysis of all the degradation phenomena identified in the complex, due to both its deterioration state and structural damage. Particular attention is placed on the bell tower that shows different degradation of the surfaces, with large erosions and fallen plasters. The masonry structure, notably compromised, shows several cracks due to the rotation of the tower towards the street. Because of such damage phenomena, a preliminary investigative research was performed to understand the effective conservation state of the Church and its appurtenances. The obtained diagnostic survey data confirm the hypotheses advanced in the cognitive phase and have provided all the necessary elements for the restoration and retrofitting design. This paper presents the restoration design and the results of the seismic analyses carried out on the bell tower.
\end{abstract}

(C) 2019 The Authors. Published by IEREK press. This is an open access article under the CC BY license (https://creativecommons.org/licenses/by/4.0/).

\section{Keywords}

Church; conservation; restoration; consolidation; seismic retrofitting

\section{Introduction}

Ecclesiastical buildings, churches and bell towers in particular, are characterized by a complex organism due to various factors such as geometry, materials, building technic, and their structural behaviour depends on some specific factors: lean structure, degree of connection between walls, presence of adjacent structures in the lower parts (which can create horizontal constraints), presence of thin architectural elements in the upper part of the structure (bell towers, very high timpani, battlements, etc.). They are the representation of the Italian background and of the evolution reflecting both social and cultural aspects of the society through a different style (Rossi, Grande, Faggella, Tarque, Scaletti \& Gigliotti, 2019). One of the most important aspects is the cultural and the artistic components of this type of structures, which is linked to a preservation of cultural heritage in order to hand it to down a posterity (Ceroni, Pecce \& Manfredi, 2009), (Milani, Shehu \& Valente, 2017). The emergency to protect structures of cultural significance derives by the fact that many of them were built with no seismic regulations and following a different rule and construction method from the ones used today (Spyrakos, 2018). The preservation of these structures is considered an essential issue in the cultural life of modern society, but it's really complexes mainly due to the 
degradation phenomena and to their structural safety (Guadagnuolo, Nuzzo \& Faella 2018), (Ferraiolo, Miccoli \& Abruzzese, 2017), (De Silva, Ceroni, Sica \& Silvestri, 2018); both these aspects are strongly influenced by the longevity and durability of these structures, so before adopting any type of interventions that aims to restoration or structural safety of buildings of the historical heritage, it is necessary to know the actual characteristics and peculiarity of any existing construction. Recently, the new Italian Building Technical code NTC 2018 ( MIT, 2018), in order to avoid the adoption of wrong or inadequate solutions, has specified a path of knowledge, mandatory before intervening on the existing heritage, which provides essential information for planning of interventions, such as the type of structure, its characteristics, the mechanical characterization of structural anon structural materials, the knowledge of masonry walls, the methods and techniques in place when these structures were built. This paper presents the restoration design and the results of some seismic analyses, performed applying the LV1 model to the bell tower of a sixteenth century masonry church in Italy, the "Santa Maria di Montedecoro Church" in Maddaloni (Italy).

\section{Santa Maria of Montedecoro Church}

The Church of Santa Maria of Montedecoro in Maddaloni, is situated in the village of Montedecoro which belongs to the town of Maddaloni, in the province of Caserta (Campania). Montedecoro is 3,43 kilometers far from Maddaloni. The historical information concerning the church are scarce and fragmentary; however, it is possible to reconstruct the main developmental phases, on the basis of the analysis of the architectural elements. The first published news concerning the construction can be read in the "Life of P.D. Carlo Carafa", in chapter XVI, entitled "Founding the house of S. Maria di Montedecoro". On that site an underground chapel was found in 1626, containing a votive image of the Virgin Mary, so Carlo Carafa bought land useful for building the new Church and to which he himself participated in the design and construction (Gisolfo, 1667). The church stands on Via Carmignano, overlooking a large courtyard, thanks to which it is possible to perceive the entire complex, which is accessed through a single central entrance which is marked by a pronaos. The Montedecoro's complex consists of the church dedicated to Virgin Mary, the bell tower which is set back from the church, the sacristy, the parsonage and a large outdoor green space, as shown in Figure 1. The church has a single nave but it is laterally divided into small chapels, that can be accessed directly from the central nave. The elevation, punctuated by a pronaos of access, is surmounted by a large rose window, surmounted in turn by a clock. The church is flanked by the tufa bell tower, which is accessed by an entrance inside the church.
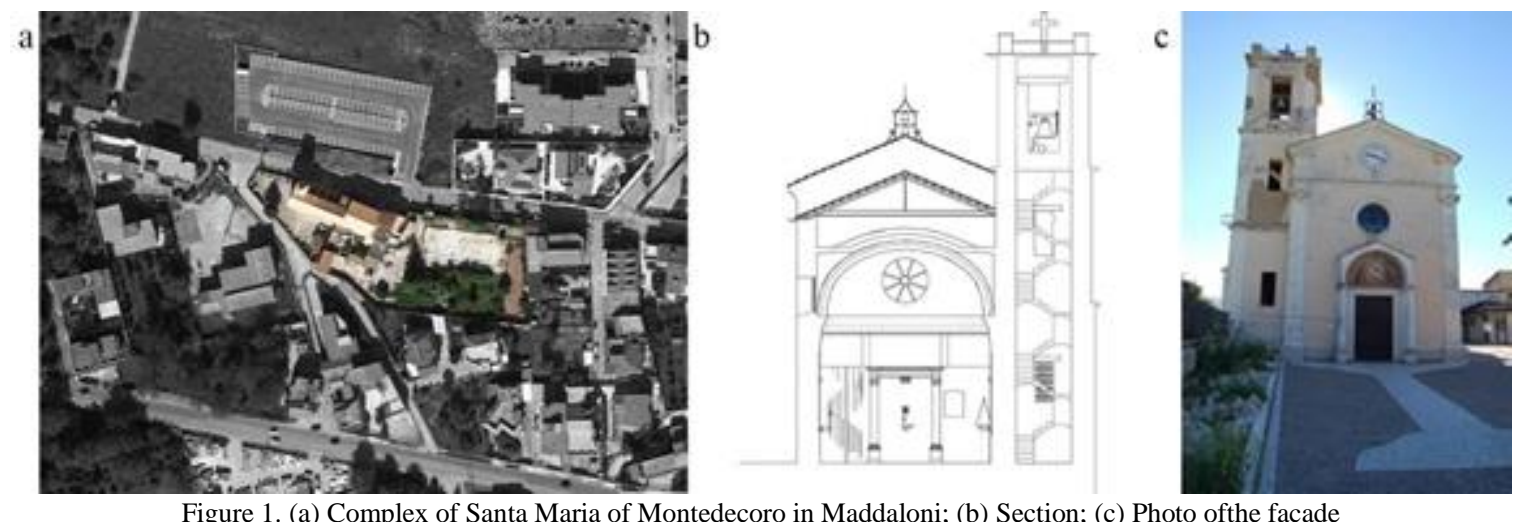

Figure 1. (a) Complex of Santa Maria of Montedecoro in Maddaloni; (b) Section; (c) Photo ofthe façade

\section{Degradation phenomena and structural damage}

The deterioration detected in the building's cognitive phase presented several features: on the outside there was a general state of degradation due to the plasters that were detached and to the painting that were damaged; the covering mantle was compromised and disconnected, depriving the Church of an adequate waterproofing. The bell tower, built in the first half of the twentieth century, had large surfaces of fallen plaster, erosion and differential degradation of the surfaces, as shown in Figure 2. Its protection has been recently modified, and now on the last roofing slab there are four tufa blocks that hold a simple protective grid, on which a bright blue PVC layer insists, in contrast with the surroundings. The interior of the church showed different type of recent interventions; in the side chapels there was a 80s-style floor, not adequate to the historical artistic environment, while the flooring of the nave was in 60s-style (in colored conglomerate). 


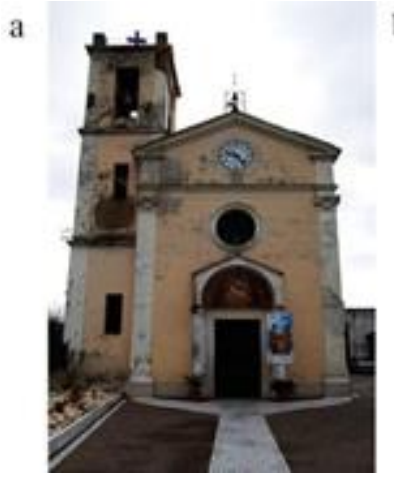

b

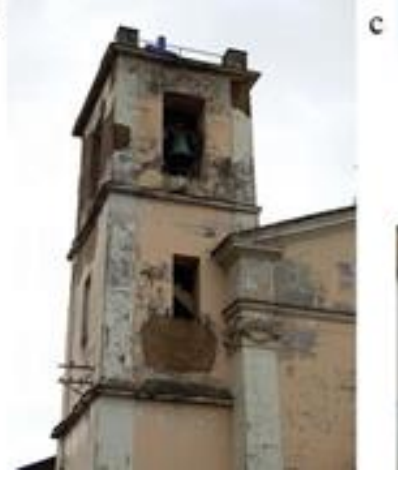

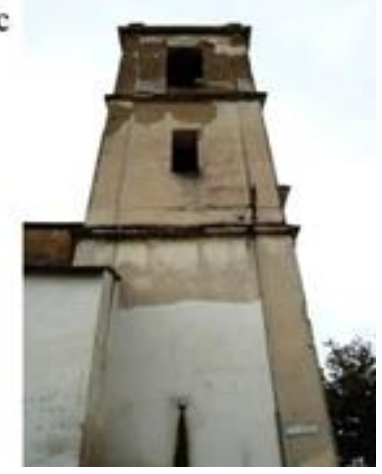

Figure 2. Degradation state of the bell tower

The structure appeared to be compromised also under the static profile, since there was an accentuated crack pattern in the bell tower, due mainly to out-of-plane overturning mechanisms. The tower had two main problems: a global overturning and a local slide due to different causes. The first probably linked to a settlement at the street level. Surveys performed at a depth of 9 meters from the street level showed that the ground between 3.50 and 5.00 meters had a significant percentage of humidity and water compared to the average, due to a loss of the water supply at few meters from the bell tower. In relation to the second problem, two sides of the church were more compromised and marked by large diagonal cracks. The mechanical phenomenon is ascribable to the sliding towards the street due to a failure of the wall structure. The global overturning was also attested by the detachment of the internal staircase from the perimeter wall of the tower with cracks that open from the bottom upwards. The accentuation of recent mechanisms and the fall of materials from the bell tower and from the church could be due to a differential movement of the foundations and to the vibrations that vehicles cause on the bumpy road surface. The bell tower, of more recent construction than the church (1942) as demonstrated by the study of the pattern bond of walls, was built by placing some new walls on church's walls. The other walls of the bell tower appears only leaning against the lateral wall of the church to which it joins. Quite frequently, bell towers are only in contact with other lower structures. In these structures, the presence of horizontal constraints at different heights can profoundly modify the seismic behaviour of the bell tower: the limitation of slenderness and the introduction of localized stiffening elements produce stress concentrations and considerably increment in vulnerability (Faella, Giordano \& Guadagnuolo, 2010). Surveys into the ground up to 1.50 meters deep along the boundary wall with the street showed a greater quantity of water under the church, mainly if compared to that found in the most superficial internal areas. The vault of the nave has a longitudinal crack and other less obvious cracks. The analysis of the upper floor showed that the roof warping was modified in recent times, laying part of the roof on the perimeter walls of the church and not on the orthogonal walls, as the original building. A part of the roof has been raised and the timber structure has been replaced with steel carpentry. This change led to a new static arrangement of the church, resulting in unforeseen lateral thrusts. In order to define the most relevant consolidation to adapt to strengthen the structure, it was necessary to assess the seismic safety of the bell tower, as shown in the following.

\section{Seismic safety assessment of the "Santa Maria of Montedecoro" bell tower}

The seismic safety of the bell tower was evaluated by the LV1 approach of the "Guidelines for the Reduction of Seismic Risk on Cultural Heritage", (DPCM, 2011). The procedure requires to evaluate the ground acceleration that leads the achievement of the limit state of activation (LSA), with a pre-set probability of overcoming in the reference period that depends on building's characteristics and use. The seismic safety is then summarized by a safety index computed as the ratio of seismic capacity to demand. This allows to underline the critical situations and to establish a priority for the interventions. The model of the bell tower was divided into three sections from bottom to top, as summarized in Table 1. The roof was considered as an overload on the last portion. The subdivision in sections corresponds to the need to obtain portions with almost uniform geometric characteristics, and depends on the level of the belfry, on the level in which there is a change in materials and on the level where was a change during the construction. The seismic analysis was carried out at each section and for four directions of the seismic input. Regarding the seismic input, the seismic parameters were computed for buildings in Class II (buildings of ordinary performance levels and normal overcrowding without dangerous elements for the environment), soil class A, 
topographical category $\mathrm{T} 1$. The peak ground acceleration ag resulted equal to $0.143 \mathrm{~g}$, the amplification factor of the soil spectrum $\mathrm{F}_{\mathrm{O}}=2.462$.

Table 1. Geometryand material of the "Santa Maria of Montedecoro" bell tower

\begin{tabular}{|c|c|c|c|c|c|c|}
\hline Section & Height $[\mathrm{m}]$ & Material & Geometry [m] & $\begin{array}{c}\text { Strength } \\
{[\mathrm{MPa}]}\end{array}$ & $\begin{array}{c}\text { Weight }[\mathrm{Kn} / \\
\text { M3 }]\end{array}$ & $\begin{array}{c}\text { Total loads } \\
{[\mathrm{kN} / \mathrm{m} 2]}\end{array}$ \\
\hline 1 & 6.43 & Tuff & $4.25 \times 4.21$ & 1.30 & 16.0 & - \\
\hline 2 & 5.44 & Tuff & $4.23 \times 3.77$ & 1.30 & 16.0 & 6.30 \\
\hline 3 & 4.59 & Tuff & $4.23 \times 3.43$ & 1.30 & 16.0 & 3.00 \\
\hline
\end{tabular}

The safety indexes were computed assuming a confidence factor of 1.25 (corresponding to complete survey of the building geometry and extended surveys of the mechanical properties of materials) and a behavior factor equal to 2 . The total loads (dead and live loads), as well as the material strength, adopted in seismic assessment are summarized in Table 1 . The minimum safety index obtained is equal to 0.84 , and shows that the bell tower is not capable to fully make forehead to the foreseen design seismic event.

\section{Restoration and retrofitting design}

The Church has required interventions aimed at the architectural restoration of the complex in a unitary manner and in compliance with the fundamental principles of conservation, such as unity of method, respect for the historical framework, possible reversibility of the interventions and compatibility of the materials used. The restoration design was drafted by one of the authors, the architect Mariano Nuzzo. The design was based both on several in situ surveys performed to know all the geometric data, the mechanical characteristics of the materials, the properties of the structural elements and on the study of previous surveys and monitoring performed on other similar buildings. In fact, the careful application of the available testing techniques provides much reliable information that allow to identify the best strengthening solution (Faella, Frunzio, Guadagnuolo, Donadio \& Ferri, 2012), (Pérez-Gracia, Caselles, Clapés, Martinez \& Osario, 2013), (Lignola \& Manfredi, 2010), (Bosiljkov, Uranjek, Zarnic \& Bokran-Bosiljkov, 2010), but the results of any previous monitoring can be crucial for the reliable design of interventions on ancient structures (Monaco, Guadanguolo \& Gesualdo, 2014), (Gesualdo, \& Monaco, 2015). Indeed, sometimes the structural conception of the building or inadequate retrofitting (Guadagnuolo, Faella, Donadio \& Ferri, 2014) are the main cause of damage or collapses. The design envisaged the pre-consoldation of the decorated surfaces of vaults, the removal of the flooring of the side chapels, the cast of traditional screeds with subsequent laying of traditional terracotta pavements and the installation of some new timber frames. The choir was covered by plywood and plasterboard panels to hide the degradation of the wood, removing the incongruous additions and cleaning the chestnut wood underneath, integrating it only where necessary. Other interventions concerned the relocation and restoration of part of the presbytery balustrade that was found in the church. The disassembly of the 70' floor in the side chapels allowed the discovery and subsequent restoration of the original terracotta floors, which were cleaned and left exposed, but also allowed to have information on how realize the new terracotta pavement (shape and size). The interventions then involved the dismantling of the marbles at the base of the largely loose and disconnected arches of the hall. The restorations carried out outside the complex concerned: the filling of the passing cracks with tuff flakes and hydraulic lime, the demolition of the incongruous additions, the recovery and reintegration of the plaster, the restoration of the stuccos, the regimentation of the rainwater through the restoration of the original paths, the painting of some walls with lime paint and natural pigments and the replacement of the marble inserts in the churchyard with porphyry cubes similar to those existing in shape, color and size, as shown in Figure 3. A new electrical system was arranged under the new flooring, trying to use the original electrical routes and limiting the new ones to the essentials (mostly realized in the side chapels, where the plasters have already been replaced several times during the years). 
a

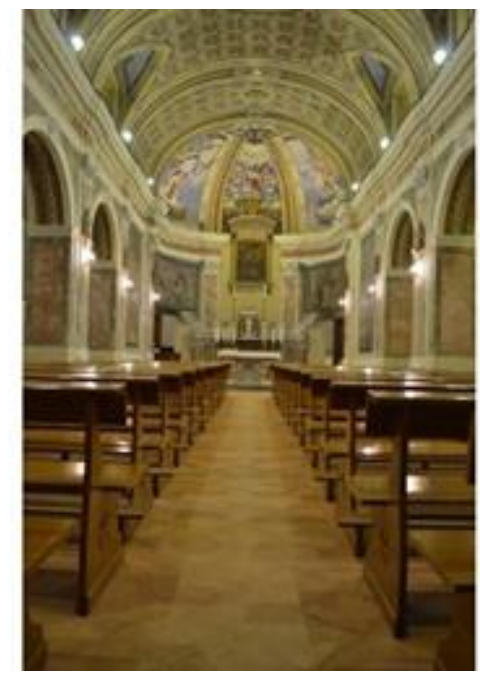

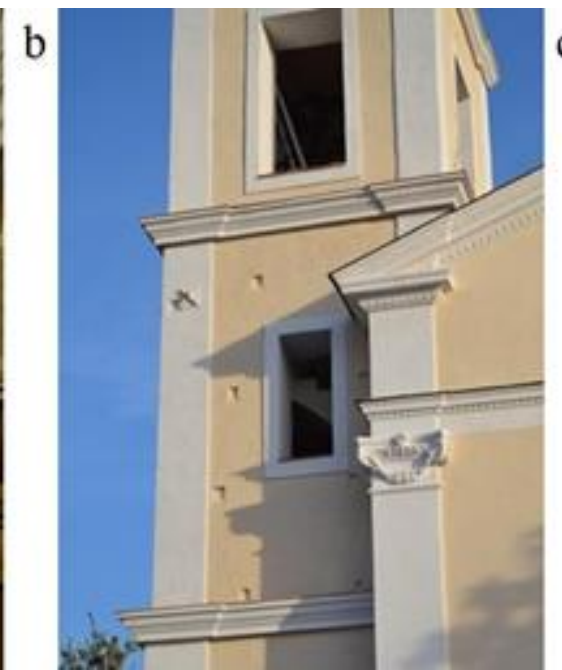

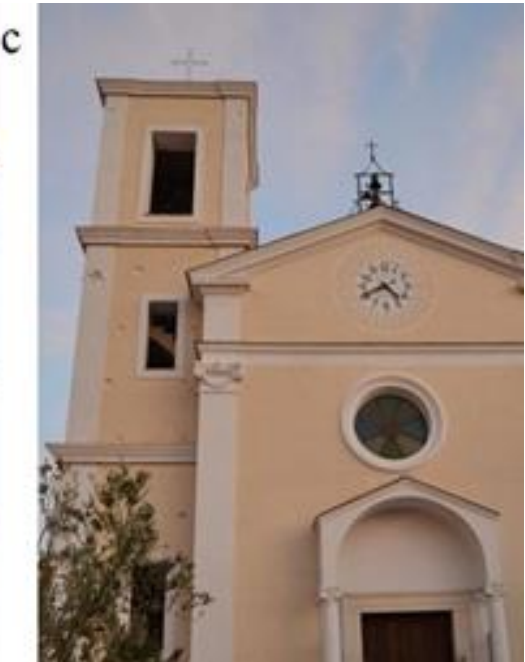

Figure 3. Church and bell tower after restoration and retrofitting

The strengthening of the bell tower structures was finalized to improve both the static and seismic capacity, on the base of the previous numerical analyses. It concerned: the realization of micro-piles for the soil consolidation and the foundation strengthening; the removing of concrete elements; the insertion of tie bars at the level of the ornamental cornices; the filling of the passing cracks with tuff and hydraulic lime; the protection of the iron elements; The rerofit or reconstruction of the damaged ornamental cornices; the demolition of the incongruous tuff structures; the installation of a new steel cross on the top of the structure. In order to ensure the outflow of meteoric water and to make the architectural issue coherent with the context, it has been realized a pyramidal shape for the bell tower termination, made by a timber structure covered with roof tiles. Finally, after the strengthening, the value of bell tower seismic safety indices were re-evaluated. The compressive strength of masonry walls was increased up to $1.6 \mathrm{MPa}$, based on the strengthening performed. The new minimum safety index was equal to 1.27, thus making the structure capable of withstanding a seismic event.

\section{Conclusion}

The paper describes a representative example of a multidisciplinary project that put together more disciplines and more skills in intervention practices. Specifically, the design for the restoration and strengthening of the bell tower of the Santa Maria of Montedecoro Church is briefly described. The restoration was aimed to give back an architectural dignity to the Virgin Mary complex, tampered by man during the last century, while letting the signs of time to shine and respecting the evolution of the whole complex, as well as to improve its static and seismic safety. As remarked by the new version of the Italian Building Technical Code, no intervention design should be separated from a preliminary study carried out through a wide and multidisciplinary project of knowledge, as an essential prerequisite for the correct planning of the structural and non-structural interventions. Many buildings of the Italian cultural heritage, indeed, show the tangible signs of the passage of time and degradation but still manage to satisfy the performance requirements for which they were created. In these cases, even if they do not appear to be particularly compromised and there is no need to radically and immediately intervene on them, the present paper clarifies how also for constructions where there are problems of a slight nature with respect to emergency situations, the architectural and structural design cannot be separated from a correct evaluation of the seismic safety index, especially given the speed and easy by which solutions and results are obtained. Also, through a simplified assessment (such as the LV1 level approach of the Italian national seismic code) it is possible to obtain results that provide essential and rapid indications for the correct planning of the rerofit, do not require particularly complex analyses, but are useful for achieving an improvement in seismic performance.

\section{Reference}

Bosiljkov. V.. Uranjek. M.. Zarnic, R.. \& Bokan-Bosiljkov, V. (2010). An integrated diagnostic approach for the assessment of historic masonry structures. Journal of Cultural Heritage. 11, 239-249. doi:10.1016/j.culher.2011.11.007.

Ceroni. F., Pecce, M.. \& Manfredi. G. (2009). Seismic Assessment of the Bell Tower of Santa Maria Del Carmine: Problems and Solutions. Journal of Earthquake Engineering, 14(1), 30-56. doi: 10.1080/13632460902988968. 
de Silva, F., Ceroni, F., Sica, S., \& Silvestri, F. (2017). Non-linear analysis of the Carmine bell tower under seismic actions accounting for soilfoundation-structure interaction. Bulletin Of Earthquake Engineering, 16(7), 2775-2808. doi: 10.1007/s10518-017-0298-0

DPCM. (2011). Valutazione e riduzione del rischio sismico del patrimonio culturale con riferimento alle Norme tecniche perle costruzioni di cui al decreto del Ministero delle infrastrutture e dei trasporti del 14 gennato 2008. Direttiva DPCM. 9(2). 54 del 26.02.2011", (in italian)

Faella, G., Frunzio, G.. Guadagnuolo, M.. Donadio, A.. \& Ferri. L. (2012). The Church of the Nativity in Bethlehem: non-destructive tests for the structural knowledge. Journal of Cultural Heritage, Elsevier, ISSN, 1296(2074), 10-1016,

Faella. G.. Giordano. A., \& Guadagnuolo, M. (2010). Unsymmetric-plan masonry buildings: pushover vs nonlinear dynamic analysis. Toronto,

Ferraioli, M.. Miccoli, L.. \& Abruzzese, D. (2017). Seismic Risk assessment of the santa Maria a Vico Bell Tower. Ambient vibration measurements and numerical model tuning. Lisbon, Portugal.

Gesualdo, A., Monaco, M., (2015). Constitutive behaviour of quasi-brittle materials with anisotropic friction, Latin American Journal of Solids and Structures, 12(4), 695-710.

Guadagnuolo, M., Nuzzo, M., \& Faella, G. (2018). The Corpus Domini Bell Tower: Conservation and Safety. Procedia Structural Integrity, 11, 444-451. doi: 10.1016/j.prostr.2018.11.057

Guadagnuolo, M.. Faella. G.. Donadio. A.. \& Ferri. L. (2014). Integrated evaluation of the Church of S. Nicola di Mira: Conservation versus safety. NDT \& E International, Elsevier. 68, 53-65.

Lignola, G. and Manfredi, G. (2010). A combination of NDT methods for the restoration of monumental façades: The case study of Monte di Pietà (Naples, Italy). Journal of Cultural Heritage, 11(3), pp.360-364.

Milani, G., Shehu, R., Valente, M.. (2017). Seismic Assessment of Masonry Tower by Means of Nonlinear Static Procedures. X International Conference on Strctural Dynamics, EURODYN

MIT. (2018, 2). Norme Tecniche per le Costruzioni, D.M. 17.01.2018. In (Vol. 42). in: Author.

Monaco, M., Guadagnuolo, M., \& Gesualdo, A. (2014). The role of friction in the seismic risk mitigation of freestanding art objects. Natural Hazards, 73(2), 389-402. doi: 10.1007/s11069-014-1076-9

Pérez-Gracia, V., Caselles, J., Clapés, J., Martinez, G., \& Osorio, R. (2013). Non-destructive analysis in cultural heritage buildings: Evaluating the Mallorca cathedral supporting structures. NDT \& E International, 59, 40-47. doi: 10.1016/j.ndteint.2013.04.014

Gisolfo P. (1667). Vita del PD. Carlo Carafa fondatore della Congregatione de' P.P. Pij operai di. Napoli. Napoli.

Rossi. E., Grande. F., Faggella. M.. Tarque. N.. Scaletti. A.. \& R, G. (2019). Seismic assessment of the Lima Cathedral Bell Towers via Kinematic and Nonlinear Static Pushover Analyses. International Journal of Architectural Heritage.

Spyrakos, C. . (2018). Bridging performance based seismic design with restricted interventions on cultural heritage structures. In Engineering Structures (Vol. 160. p. 34-43).

\section{Acknowledgments}

The contribution of Ministry of Education, University and Research and particularly the Basic Research Activities Fund (FFABR) is gratefully acknowledged.

The Laocoonte Research Consortium is gratefully acknowledged for the collaboration and willingness shown in providing data and software. 